Article

\title{
Integrating Social Values and Ecosystem Services in Systematic Conservation Planning: A Case Study in Datuan Watershed
}

\author{
Yu-Pin Lin ${ }^{1, *}$, Wei-Chih Lin ${ }^{2}$, Hsin-Yi Li ${ }^{3}$, Yung-Chieh Wang ${ }^{4}$, Chih-Chen Hsu ${ }^{1}$, Wan-Yu Lien ${ }^{1}$, \\ Johnathen Anthony ${ }^{1}$ and Joy R. Petway ${ }^{1}$ \\ 1 Department of Bioenvironmental Systems Engineering, National Taiwan University, Taipei 10617, Taiwan; \\ cchsuntu@ntu.edu.tw (C.-C.H.); wanyulien@gmail.com (W.-Y.L.); f03622040@ntu.edu.tw (J.A.); \\ d05622007@ntu.edu.tw (J.R.P.) \\ 2 Geographic Information Technology Co., 4F., No. 310, Section 4, Zhongxiao E. Road., Taipei 10694, Taiwan; \\ b97602046@ntu.edu.tw \\ 3 Fong-Yi Construction Co., LTD., 20F.-2, No.501, Section 2, Taiwan Blvd., West Dist., \\ Taichung City 403, Taiwan; r01622011@ntu.edu.tw \\ 4 Department of Water and Soil Conservation, National Chung Hsing University, No. 145, Xingda Road, \\ South District, Taichung 402, Taiwan; wangyc@nchu.edu.tw \\ * Correspondence: yplin@ntu.edu.tw; Tel.: +886-3366-3467
}

Academic Editor: Marc A. Rosen

Received: 12 January 2017; Accepted: 21 April 2017; Published: 29 April 2017

\begin{abstract}
Systematic conservation planning (SCP) deals with a delicate interplay of competing interests and has far-reaching impacts for all stakeholders and systems involved. While SCP has traditionally attempted to conserve ecosystem services that benefit ecological systems, public perceptions of conservation initiatives influence their ultimate feasibility and sustainability. In an attempt to balance ecological integrity, social utility, and urban development, this study develops a framework that applies four popular models to represent these competing factors, including two ecosystem services models-InVEST (Integrated Valuation of Environmental Services and Tradeoffs) for biophysical services (BpS), and SolVES (Social Values for Ecosystem Services) for social values (SV); a land use and land cover (LULC) suitability model; and Zonation for delimiting high priority areas. We also analyze a number of conservation scenarios that consider varying levels of urban development. While BpS are distributed with considerable spatial variability, SV spatially overlap. Approximately $6 \%$ of the area was identified as having both high BpS and SV, whereas a further $24.5 \%$ of the area was identified as either high BpS low SV or vise-versa. Urban development scenarios affected the conservation area selection drastically. These results indicate tradeoffs and potential synergies between development, SV, and BpS. Our findings suggest that the information provided by the proposed framework can assist in finding solutions to social-ecological planning complexities that serve multiple stakeholders.
\end{abstract}

Keywords: ecosystem services; social values; systematic conservation planning (SCP); biophysical services (BpS); social values (SV); conservation strategy; social-ecological matrix

\section{Introduction}

Ecosystem services (ES) are generally defined as the ways in which ecosystems benefit humans but can be better understood as a collection of support, supply, regulating, and cultural services that provide direct and indirect benefits to everyone [1,2]. Numerous ES studies have identified the potential analytical power the social-ecological system concept has in understanding the dynamic interactions between environmental and social change [3,4]. When addressing global and local resource 
scarcity and utilization change issues, approaches that combine social and ecological factors may also assist in conflict alleviation and resolution [5]. Given the increased impacts of these dynamics (e.g., urbanization, habitat degradation, resource overexploitation, climate change, and invasive species expansion), such approaches are critical in safeguarding against ES degradation. Although it is widely recognized that ES result from complex interactions between social and ecological systems [6,7], it remains unclear which precise combinations of social and ecological contributions are required to produce services. It is also unclear how these combinations affect the resilience and sustainability of the provisioned services [8]. Therefore, it is important to quantify ES, using both social values (SV) and biophysical services (BpS) to address the growing demand for ES in our societies and to evaluate the benefits of ES as a whole [9-13].

ES has been quantified by various models such as the Integrated Valuation of Environmental Services and Tradeoffs (InVEST) model which generates spatially explicit estimations of ES and renders natural capital maps at the pixel level [14-18]. Although many studies have explored support, supply, regulating, and cultural ES, the cultural aspects of ES, which reflect the emotional and spiritual attachment of a society to its environment, are relatively scarce. Developing a robust yet standard and scalable set of ES, for local and broad national-level policies, that is rooted in both social and ecological values is challenging. Therefore, standardized methods to quantify and map all aspects of ES are notably absent from the majority of decision-making processes in natural resource management [19]. Fortunately, with recent technological advances we can now increase data availability for quantifying SV via crowdsourced data, i.e., data garnered from online sources [20]. With research tool improvements and the neogeography evolution, we can map and model SV with the Social Values for Ecosystem Services (SolVES) [21,22] application to assess public thoughts, and ES demand.

Daily et al. [23] argue that in resource management and conservation planning, SV information is critical and should be included when developing effective decision-making frameworks that support ES-based approaches. Nevertheless, quantitative SV information is notably excluded from most existing ES valuation efforts. Various studies from numerous fields have drawn attention to the need for SV inclusion in ES valuation [9-13,24-30].

Web 2.0 technologies, i.e., social media platforms (e.g., Facebook, Twitter, YouTube, and Flickr), are revolutionizing data collection efforts [31]. Such platforms and technologies can galvanize citizen science initiatives, thereby increasing the amount of spatiotemporal data available through crowdsourcing [31]. In fact, a growing number of conservation studies have also relied on social media platforms to extract data [32-34]; other studies have discussed the reliability of crowdsourced data $[31,35,36]$. For example, contributed geographic information (CGI), volunteered geographic information (VGI), citizen sensors or collaborative information with social media platforms have been utilized for aesthetic evaluations of the landscape [37-41], place-specific psychological attachment [42], or local identity and existence values [43]. Many of the above-mentioned studies have used interesting methods to assess social values, such as analyzing the number of photographs taken of specific sites to quantify the place-specific importance of cultural ecosystem services [41,43].

Beyond data collection subsequent ES modelling and prioritization is an essential step since it allows decision makers to better allocate limited resources [44]. The Systematic Conservation Planning (SCP) approach quantifies the relative importance of different areas, thereby supporting the design and evaluation of conservation areas [45]. Although conservation policy makers have historically overlooked SV, due to a lack of available quantification and zonation methods, it is now possible to assess both SV and BpS much more accurately. This allows for the integration of SV and BpS which assist in the decision-making process $[3,46]$. Moreover, various contemporary studies have gained further understanding of the relationships between social and ecological systems by using approaches that utilize a social-ecological framework. Specifically, a recent study by Ban et al. [47] proposed integrating the zonation of SV with BpS under a socio-ecological system framework.

ES mapping emphasizes the ecological provision and benefits of landscape characteristics for human well-being in the context of spatial relationships [48]. In order to ensure that future ES supply is 
a prioritized political agenda item, spatially explicit assessments of quantified ES supply and demand must inform decision-making processes [17,19,38,49-51]. One of the persistent challenges facing conservationists worldwide is maintaining multiple ES by making appropriate compromises when tradeoffs are necessary [52]. Thus, this paper develops a conservation area selection strategy using the Datuan catchment region of Taiwan to test the proposed strategy. The strategy makes use of four models, including InVEST, the SolVES model, SCP zonation, and a land use land cover (LULC) suitability model, to evaluate the spatial distribution of SV and BpS to better assess ES as a whole. We also utilize a crowdsourced dataset, which Li [53] validated. Throughout this paper, ES are defined as the combined returns of SV and BpS. We use "SV" to refer to outputs from SolVES, whereas "BpS" refer only to those outputs from InVEST. This paper makes two main contributions, including a method to combine SV and BpS via prioritization of conservation areas using SCP zonation, and the proposed conservation strategy for the target area using a social-ecological matrix.

\section{Materials and Methods}

Figure 1 illustrates the basic framework of this study. As can be seen, the aim was to compare and contrast high priority BpS areas with SV areas as identified by the zonation SCP model under varying development scenarios, i.e., land allocation regimes. We achieved this by creating a social-ecological matrix that identifies the extent to which high priority BpS and SV areas overlap. In the first step, InVEST generated six biophysical ES maps based on location-specific biophysical data, whereas SoLVES generated 12 social ES maps based on data derived from questionnaire results. The land use suitability maps, which ultimately dictate future land use change, are then calculated based on both land use allocation maps (from previous years) and direct drivers (environmental variables). SCP zonation then generated 6 spatial prioritization scenarios based on different inputs. The zonation results were then compared in multiple objective programming via social-ecological matrix analysis. The results of this comparison can inform decision makers and prompt further discussion about conflicting priorities.

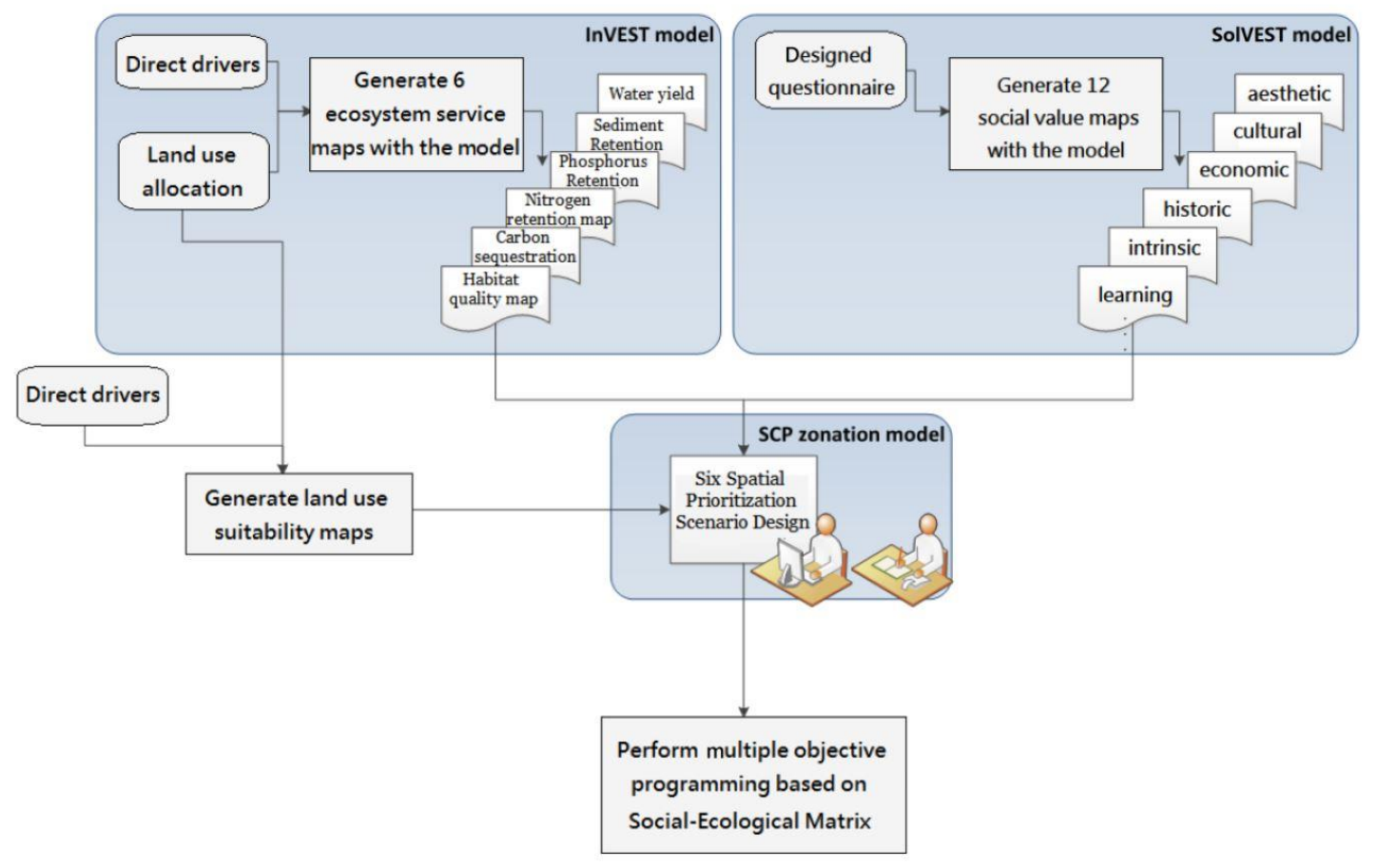

Figure 1. Flowchart and study design. 


\subsection{Research Area}

Datuan Watershed is located in northern Taiwan and begins at the bottom of Siaoguanyin Mountain's (1066 m) volcano entrance, at the intersection of Yuan-Shan and Dianzi Villages, within Sanzhi District, New Taipei City (Figure 2). Overall, the total length of Datuan Stream is $14.5 \mathrm{~km}$ and the watershed covers $15.68 \mathrm{~km}^{2}$, with an average slope of $7.5 \%$. Additionally, it is the third largest stream within Tamsui District and is managed at the national level [54]. Datuan Watershed maintains a subtropical monsoon climate with northeastern and northern monsoons in the winter, and southeastern and eastern monsoons in the summer. Monsoons and typhoons are also common in the fall season. Annual wind blows predominantly from the northeast, while annual precipitation is $3000 \mathrm{~mm}$ with the heaviest rainfall in December. The average temperature is 22 degrees Celsius, with a monthly average peak of 28 degrees Celsius (July) and a low of 15 degrees Celsius (January). A large number of BpS are provided by the Datuan Watershed, which consists of riverine and forest ecosystems that sustain aquatic and coastal species habitats and provides other services such as carbon sequestration. In addition to BpS, the Datuan Watershed has rich cultural and historic background. For example, there is an historic bridge, Sanbanqiao, located upstream at Dianzi Village in the Sanzhi District, that was built during the Qing Dynasty under the rule of Emperor Tongzhi, circa 1856 to 1875 (see details in Supplementary). The value that Datuan Watershed lends to both society and biodiversity justifies developing conservation strategies and conservation areas in general. Datuan Watershed LULC is shown in Figure 2.

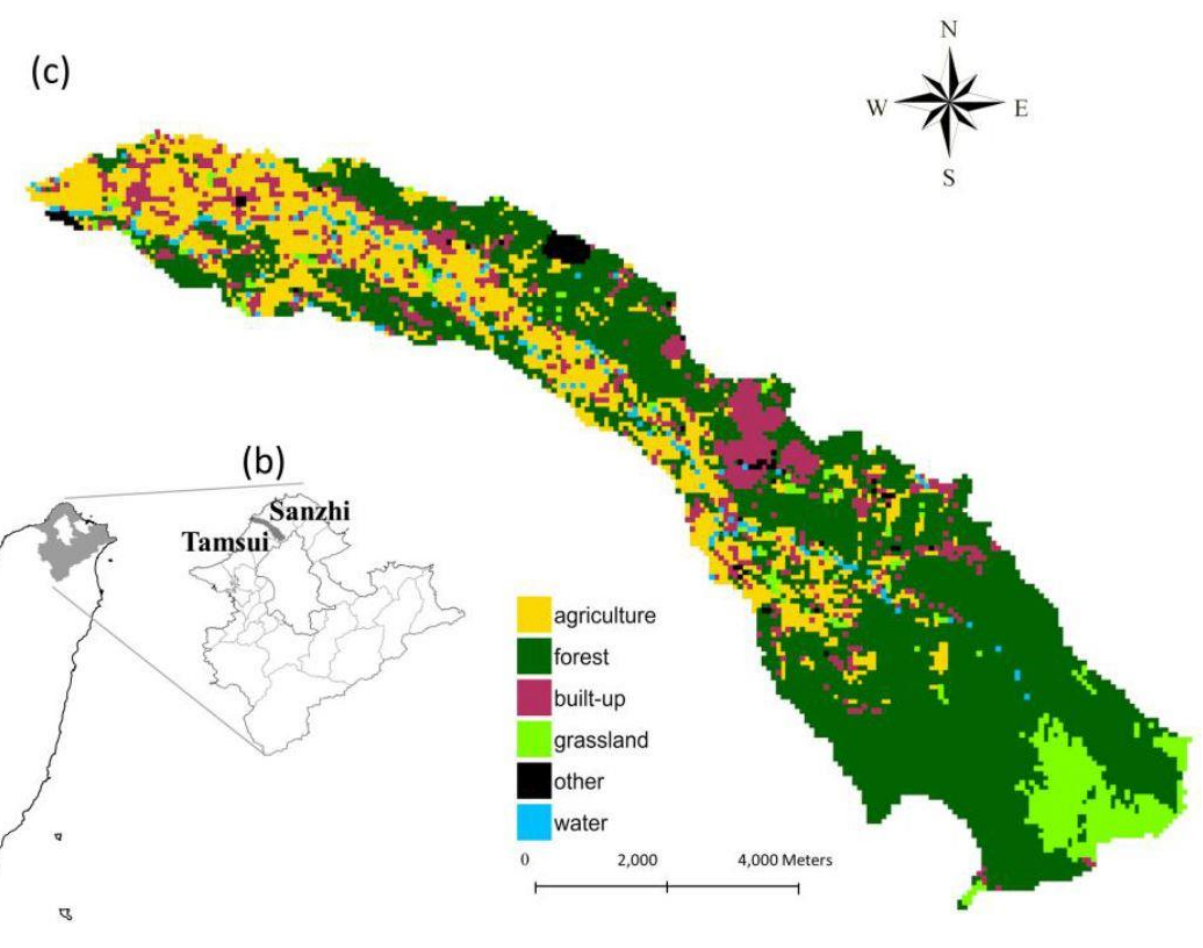

Figure 2. (a) at bottom left: Taiwan with the location of the study area, New Taipei City, highlighted in grey; (b) at center: New Taipei City with the location of the study area, at the border of Tamsui and Sanzhi, highlighted in gray; (c) at right: the LULC (land use and land cover) types of the Datuan Watershed study area. (Construction and Planning Agency of the Ministry of Interior).

The study area is divided into $50 \mathrm{~m}^{2}$ cells that span 128 cells $(6.4 \mathrm{~km})$ by 211 cells $(10.6 \mathrm{~km})$. LULC was classified into the following six categories: forested land, built-up land, agricultural land, grassland, water, and bare land. LULC maps from 2008 were utilized, which were generated and digitized in a vector format by the Construction and Planning Agency of the Ministry of Interior Taiwan based on 1:5000 aerial photographs taken in 2008. The proportions of classified LULC are as 
follows: agricultural land $25 \%$, forest $57 \%$, built-up area $9 \%$, grassland $6 \%$, water body $2 \%$ and bare land $1 \%$.

\subsection{Ecological Service Model (InVEST)}

InVEST is a suite of free, open source software models for Geographic Information System(GIS) mapping commonly used to evaluate ES [14]. This research used InVEST 2.3.0 version (The Natural Capital Project, Stanford, CA, USA) to model changes in BpS, including carbon storage, habitat quality, water yield, nitrogen retention, phosphorous retention, and sediment retention in the research area. The InVEST model divided carbon calculation into two categories: carbon storage and carbon sequestration. In the InVEST model, carbon sequestration is assessed as the current carbon pool stored in the landscape or stored over a period of time based on different LULC (i.e., wood harvest rates, harvested product degradation rates) and four carbon pools (i.e., aboveground biomass, belowground biomass, soil, and dead organic matter) [14]. Habitat quality is determined using several grid files that contain data on LULC types for each grid cell. A habitat quality map produced from this data informs decision makers on appropriate conservation areas (e.g., forest or woodland). As noted in the InVEST user guide, four factors are used in calculating habitat quality and rarity (i.e., the level of legal protection of the land, the relative threat, distance from threat to habitat, and the sensitivity of habitat types to specific threats) [14,17]. Therefore, the InVEST model requires LULC maps, data on LULC type sensitivity to specific threats, distribution and threat intensity, as well as spatial data on protected areas for use as model inputs [14,17]. Besides the LULC data layer, the InVEST model requires additional information (e.g., density of habitat risk) on different natural processes or human activities, and their corresponding impacts on habitat quality. In our model, farmland, roads, and built-up LULC were considered threats, whereas forest, riparian, and grassland LULC were considered habitats. For all of the above parameter values and model settings, such as relative threat levels, the distance decay relationship between threats etc., we used values from Chiang et al. [17] and Lin et al. [18].

For other, more hydrologically-oriented BpS, the InVEST Reservoir Hydropower Model comprises three factors: water yield, water scarcity, and hydropower production and valuation. For the purpose of this study however, a standalone water yield model based on the Budyko curve [14] calculated from annual average precipitation was used to determine the water yield BpS value. Nutrient retention estimates were based on the extent to which vegetation and soil contribute to runoff water purification and contaminant removal processes. This Nutrient Retention Model within the InVEST suite determines the nutrient retention capacity for current and future LULC scenarios by using biophysical data on water yield, LULC, nutrient loading and filtration rates, and water quality standards (if available). While different LULC types produce different ratios of nutrient production and retention, this research uses Chiang's et al. [17] nutrient retention data as reference values. Following a revision of the nutrient retention capacity, we further determined nutrient distribution pathways based on elevation, then calculated the nutrient retention and production in each grid cell. This calculation method, however, excludes potential biogeochemical processing of these nutrients. The InVEST Sediment Retention Model provides the modeler with a tool to calculate annual soil loss based on different types of LULC. As for a soil loss equation, the InVEST model uses the common Universal Soil Loss Equation (USLE) calculation method with a grid cell size unit [14] when determining sediment retention values.

\subsection{Social Value Model (SolVES)}

In this research, using crowdsourced data from Li [53] that was based on the SolVES survey format (see detail in Supplementary), we examine 12 SV including aesthetic, biological diversity, cultural, economic, future, historic, intrinsic, learning, life sustaining, recreation, spiritual, and subsistence values at 29 reference location types and 46 corresponding representative location sites selected by local elected leaders. Screening yielded a crowdsourced sample size of 101 online survey results. In terms of basic survey statistics, among the 101 respondents, $48 \%$ were female, $86 \%$ were in 
the age group of $15-35$ years, $73 \%$ reside in a household with four family members, and $64 \%$ had completed post-secondary degrees. The details of the demographic profiles of respondents are shown in Figure S2 (Supplementary Materials). Care was taken in conveying and confirming that all of the survey participants fully understood the questions, concepts, and themes of the study (see detail in Supplementary Materials). Furthermore, for the Public Participation GIS (PPGIS) portion of Li's study [53] and likewise the crowdsourced data used in this study, only those participants who met minimum knowledge requirements of natural systems and familiarity with the local landscape [55] were chosen. The vetting methods prescribed by Fagerholm et al. [56] and the Cronbach's alpha were also used to analyze the reliability, i.e., the reproducibility and internal consistency, of the survey. Other survey design statistics were also calculated to assess the necessity of including certain question categories in the survey. These included the mean, variance and correlation between survey items after questions related to the categories of: environments; culture and history; community activities and economic activities were removed. In addition, to avoid the introduction of additional spatial bias, crowdsourced participants were restricted from adding additional locations to the list of reference location sites. A standardized SV index with a ten-point scale ranging from 0 (least important) to 10 (most important) based on SolVES output values was used for all surveys.

SolVES is a GIS application and ecosystem assessment tool, developed jointly by the United States Geological Survey (USGS) Rocky Mountain Geographic Science Center (RMGSC), and the University of Colorado, that integrates and quantifies the spatial data of SV so as to inform decision makers. By considering non-monetary value indices, the application spatially represents the relationships between physical environmental conditions and SV within a target area [21]. While ES quantification tools in the past commonly have only used biophysical models, SolVES quantifies then maps SV and perceived ES in spatiotemporal models using spatial and non-spatial responses to public attitude and collective preference data gathered from surveys. Based on the customized topology, SolVES then calculates a quantitative 10-point "value index", where 10 represents the highest value, by using value-allocation responses in the survey [22]. Following this, the preference survey results are then mapped on to the topography showing quantified SV [57]. The relationship between values and environmental data, such as elevation, distance to water, land-cover type, and other physical attributes of the landscape is analyzed according to the respondent-mapped locations associated with each value type. For sites where there is no survey data available, historic landscape data and their corresponding metric data values are used. SolVES also explores differences in values among various respondent groups based on demographics and additional respondent information [22]. Moreover, SolVES validates the Maxent model used in mapping SV by setting aside $25 \%$ of the point data for any $\mathrm{SV}$ as a test dataset, and calculates both a training Area Under the Curve (AUC) and a test AUC [58]. Further details on SolVES calculation methods can be found in the SolVES user manual [59]. In this study, beyond spatial realizations of SV, we also determine the relative importance of different variables in predicting SV. We accomplished this by calculating the relative contribution of each driving factor within the SolVES model.

\subsection{Land Use and Land Cover Suitability}

In this study, driving factors (i.e., demography, infrastructure, geomorphology, soil properties, altitude, slope, distance to river, soil erosion coefficient, soil drainage, distance to major road, distance to built-up areas, distance to urban planning areas, and population densities) of anthropogenic development were used as secondary variables to calculate built-up suitability within each cell using logistic regression [60] as follows:

$$
p_{i}=\frac{\exp \left(\beta_{0}+\sum_{j=1}^{k} \beta_{j} x_{j i}\right)}{1+\exp \left(\beta_{0}+\sum_{j=1}^{k} \beta_{j} x_{j i}\right)}
$$


and

$$
\log i t\left(y_{i}\right)=\ln \left(\frac{p_{i}}{1-p_{i}}\right)
$$

where $p_{i}$ is the suitability of the built-up type in grid cell (pixel) $i ; \beta_{0}$ is the estimated coefficient of the factors in the regression; $\beta_{j}$ is the coefficient of each driving factor; $k$ is the number of local driving factors; $x_{j i}$ is the value of the local driving factor $j$ of each cell $i$; and $y_{i}$ is the dependent indicator variable (whether or not the built-up type occurs) in grid cell $i$ in the logistic regression model.

\subsection{Spatial Prioritization}

Zonation is a SCP model that supports decision-making [46]. It is applicable to conservation methodologies and quantitatively considers multi-targeted species, habitat quality, and the connections between habitats to further facilitate species conservation planning. Zonation model results often exhibit highly connected landscape structures that can be modified to present differing conservation levels within a target area by ranking model outputs. This facilitates multi-targeted conservation planning approaches with competing factors by informing ecological researchers and planners with analysis of explicitly identified and prioritized conservation areas. Basically, zonation ranks the target area using a zonation meta-algorithm. The algorithm calculates marginal loss of each grid cell when values (inputted by the modeler) are systematically removed from the target area. In this study, grid cells that caused the least marginal loss were systematically removed in order to maximize the area's connectivity and biodiversity. Marginal loss is calculated as follows [61]:

$$
\delta_{i}=\sum_{j} \frac{Q_{i j}(S) w_{j}}{c_{i}}
$$

where $\delta_{i}$ is the conservation marginal loss of grid cell " $i$ "; " $w_{j}$ " is the weight of target value " $j$ "; " $c_{i}$ " is the cost of adding grid cell " $i$ " into the conservation area; " $Q_{i j}$ " is the percentage of the distribution of BpS and SV " $j$ ", present in grid cell " $i$ ", within the remaining grid cell " $S$ " $[46,62]$. Throughout the calculation, the grid cells which are least important are first removed while more important grid cells are removed later and are considered to have higher conservation priority. Unlike general calculations that add grid cells into proposed conservation areas, this approach views every proposed conservation area as a complete conservation site from which grid cells are then removed. Controlled loss allows the conservation planner to obtain better area connectivity. If the target planning area is relatively large, the modeler can choose to remove more than one grid cell in order to accelerate the calculation time. It should be noted that results that include more than one grid cell removal per iteration are not as accurate as those of single-cell removal. For this study, a standardized removal ranking scale from 0 to 1 was used, where 0 represents the least important area and 1 represents areas of the highest conservation priority.

In order to provide decision makers with a comparison between different conservation policies under different circumstances, this research modified the scenarios of Whitehead et al. [3] for six scenarios (Table 1). The six scenarios are based on various combinations of BpS, SV, and development preferences. Note that all of the output values of BpS expressed in the table and elsewhere throughout the text is the total amount in each $50 \mathrm{~m}^{2}$ cell, with the exception of habitat quality. Habitat quality is represented by a value from 0 to 1 , where 1 is the highest. All of the InVEST biodiversity model [14] and parameter settings were based on Chiang et al. [17]. 
Table 1. Spatial prioritization and development scenarios with itemized descriptions.

\begin{tabular}{|c|c|}
\hline Scenario & Output Description \\
\hline 1. $\mathrm{BpS}^{*}$ & $\begin{array}{l}\text { 1. carbon storage }(\mathrm{mg}) \\
\text { 2. habitat quality }(-) \\
\text { 3. nitrogen retention }(\mathrm{kg}) \\
\text { 4. phosphorous retention }(\mathrm{kg}) \\
\text { 5. soil retention (ton) } \\
\text { 6. water yield }(\mathrm{mm})\end{array}$ \\
\hline 2. SV & $\begin{array}{l}\text { 1. aesthetic } \\
\text { 2. biological diversity } \\
\text { 3. cultural } \\
\text { 4. economic } \\
\text { 5. future } \\
\text { 6. historic }\end{array}$ \\
\hline 3. BpS and SV & A combination of scenarios one and two \\
\hline 4. Built-up suitability & $\begin{array}{l}\text { No BpS or SV considered and no restriction on development of areas } \\
\text { which are suitable for development based on LULC suitability model }\end{array}$ \\
\hline $\begin{array}{l}\text { 5. BpS and SV including area of } \\
\text { high development suitability }\end{array}$ & $\begin{array}{l}\text { A combination of scenarios three and four, where built-up suitability is } \\
\text { a cost to conservation }\end{array}$ \\
\hline $\begin{array}{l}\text { 6. BpS and SV excluding area of } \\
\text { high development suitability (with } \\
\text { a threshold of } 0.7 \text { ) }\end{array}$ & $\begin{array}{l}\text { Conservation prioritization that excludes areas that are highly suitable } \\
\text { for development }\end{array}$ \\
\hline
\end{tabular}

\subsection{Multiple Objective Programming}

The Social-Ecological Matrix has been used as a conservation area selection method in previous works [24,63], with the aim to keep decision makers informed of recommended strategies and conservation priorities. A Social-Ecological Matrix was designed for this study by classifying the study area into four categories based on consistency between high priority areas for SV and BpS (Table 2), including high SV-high BpS (high-high), high SV-low BpS (high-low), low SV-high BpS (low-high), and low SV-low BpS (low-low). For this study, high Social-Ecological Matrix areas correspond to the top $30 \%$ areas identified by zonation for SV and BpS models, whereas the low areas correspond to the bottom $70 \%$ low priority areas as identified by zonation.

This follows the method introduced by Whitehead et al. [3] who developed an ordering graph for both SV and BpS through zonation calculation then analyzed the multi-layered graph with the Social-Ecological Matrix. Though threshold value determination is based on different policy requirements, both Bryan et al. [24] and Whitehead et al. [3] used 20\% and 30\% as threshold values in their research, while McPhearson et al. [63] set a median as his threshold for efficiency and the facilitation of discussion.

Table 2. Social-Ecological Matrix value categorization, reflecting the relative socio-ecological importance of pixels based on SolVES (row wise) and InVEST (column wise).

\begin{tabular}{cccc}
\hline \multirow{2}{*}{ Ecosystem Services } & \multicolumn{2}{c}{ Biophysical Services } \\
\cline { 2 - 3 } & & High & Low \\
\hline \multirow{2}{*}{ Social Values } & High & High-High & High-Low \\
\cline { 2 - 3 } & Low & Low-High & Low-Low \\
\hline
\end{tabular}




\section{Results}

\subsection{Spatial Distributions of Biophysical Services}

Figure 3 shows the geographical distributions of six BpS. Since forested land contributes the greatest amount of carbon sequestration service among all LULCs, high carbon storage areas and forest areas overlapped near perfectly at the dark green points in Figure 3a. Habitat quality (Figure 3b) was higher in the remote southeast of the study area where buildings, roads and other human disturbances are not present. Since agricultural activity is a primary source of nitrogen and phosphorous emissions and accumulation, the spatial distribution of nitrogen retention and phosphorus retention (Figure 3c,d) are concentrated in downstream locations of Datuan where nearly all farms are located and where, historically, there are higher rates of soil erosion. Conversely, areas with high soil retention values (Figure 3e) were almost entirely located upstream. The spatial distribution of water yield (Figure 3f) was mostly concentrated along the Datuan Stream.

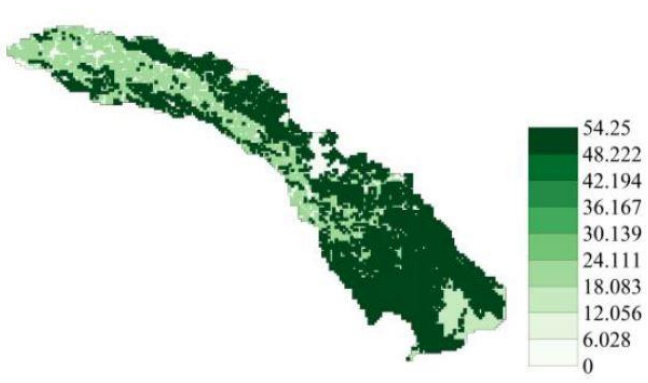

(a)

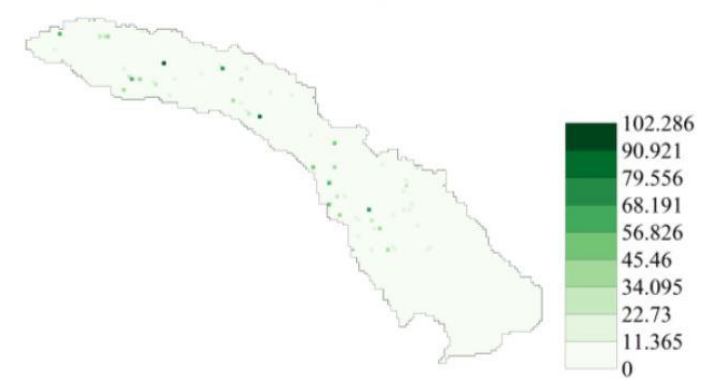

(c)

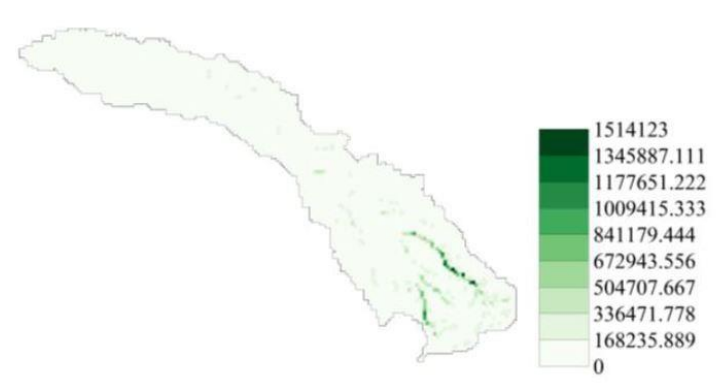

(e)

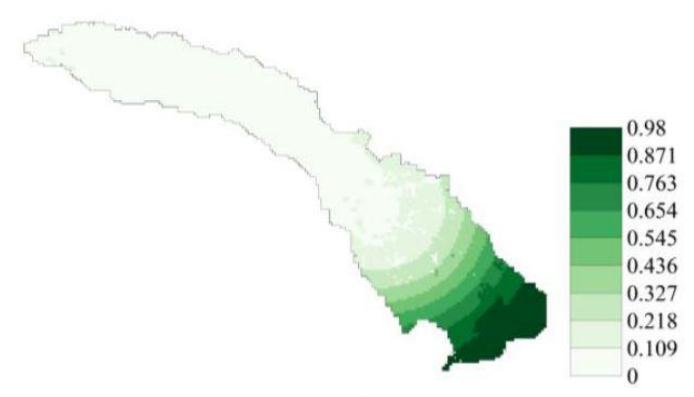

(b)

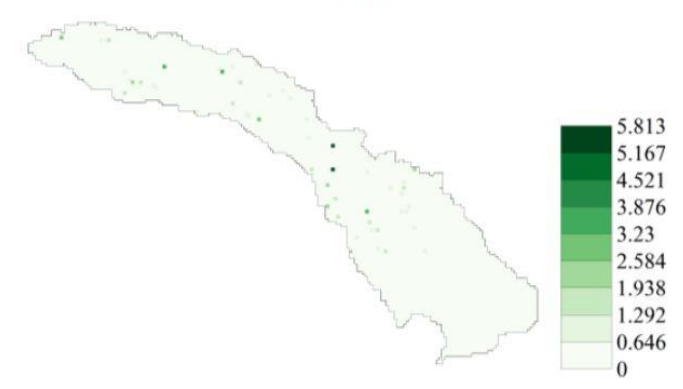

(d)

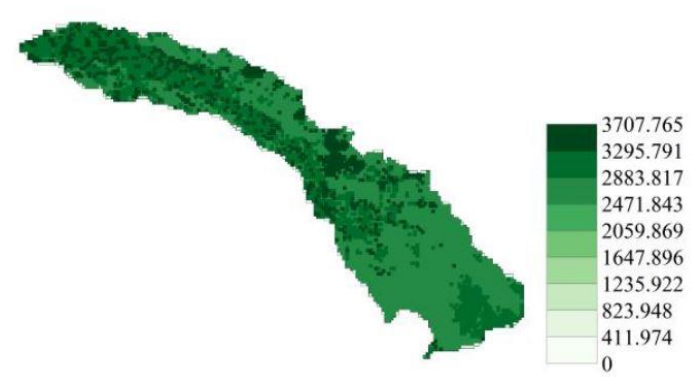

(f)

Figure 3. Spatial distributions of BpS from InVEST (Integrated Valuation of Environmental Services and Tradeoffs): (a) carbon storage (Mg); (b) habitat quality (-); (c) nitrogen retention (kg); (d) phosphorous retention $(\mathrm{kg})$; (e) soil retention (tons); (f) water yield (mm). Note: Biophysical Services (BpS). 


\subsection{Spatial Distributions of Social Values and Survey Statistics}

Since the spatial distribution of the $12 \mathrm{SV}$ outputs displayed significant overlap, i.e., they exhibited a high degree of spatial consistency, Figure 4 shows the mean and variance of the 12 SV outputs rather than 12 individual SV maps. To view the outputs of each SV individually, please see Supplementary Figure S5. As can be seen from Figure 4, the highest SV values are located along the Datuan Stream, indicating that local residents perceive the Datuan Stream as the main contributor of ES. Table 3 lists the percent contributions that each explanatory variable had in modeling the $12 \mathrm{SV}$. The "distance to stream" (Ds) variable was highest among all the environmental factors in all 12 SV models with the exception of the 'cultural' SV. The AUC values of the SolVES Maxent model for both the training and test data ranged from $0.976-0.989$ and $0.954-0.986$ (Table S5), respectively.

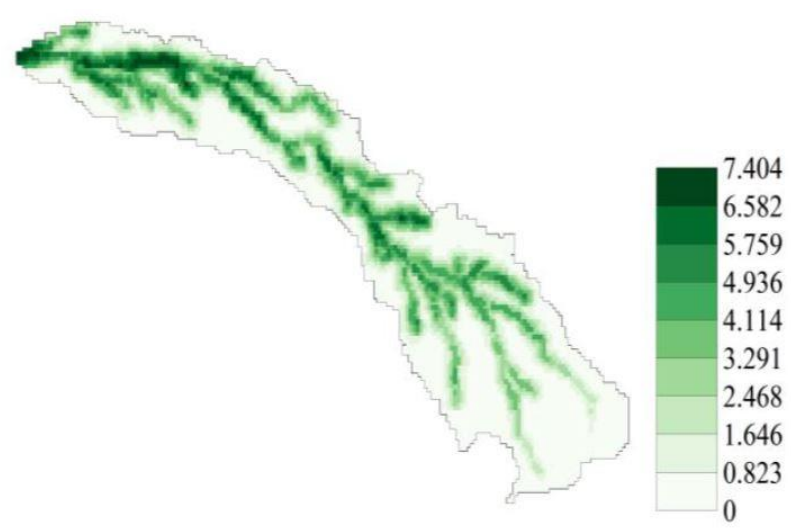

(a)

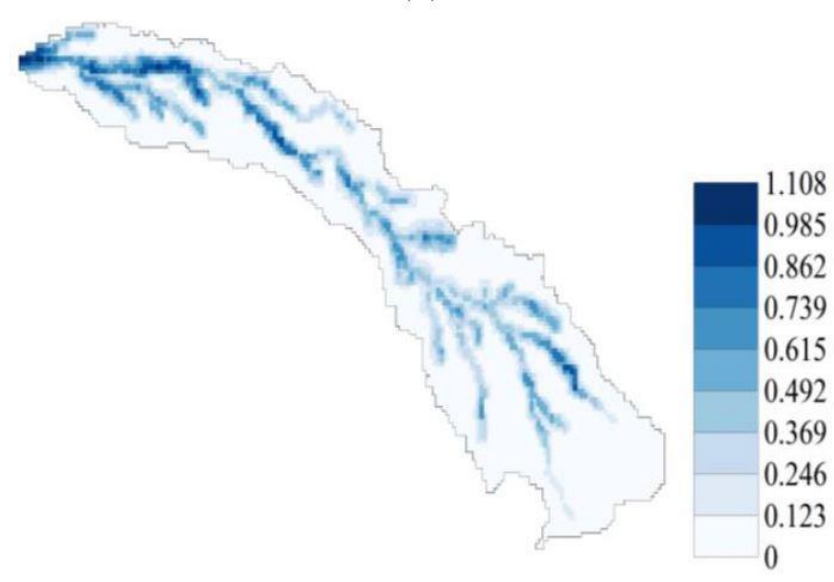

(b)

Figure 4. (a) The mean of 12 SV outputs, where higher values and darker colors correspond to higher SV importance; (b) the variance of 12 SV outputs. Note: Social Values (SV). 
Table 3. Relative contribution (expressed as a percent) of each environmental variable to modeling the $12 \mathrm{SV}$.

\begin{tabular}{ccccccccccc}
\hline Type of Value & Ds & Dr & Slope & Da & Df & Dbt & Dg & Db & Dw & LULC \\
\hline aesthetic & $40.2^{*}$ & 9.0 & 13.1 & 6.5 & 2.5 & 3.8 & 7.5 & 5.9 & 10.3 & 1.2 \\
biological diversity & $43.3^{*}$ & 8.0 & 8.7 & 5.0 & 4.8 & 7.1 & 7.4 & 6.4 & 8.9 & 0.4 \\
cultural & 13.3 & 20.7 & 9.7 & 3.2 & 4.1 & 3.7 & 12.7 & $22.9 *$ & 8.3 & 1.4 \\
economic & $37.7^{*}$ & 8.7 & 6.5 & 4.5 & 2.7 & 4.6 & 7.7 & 6.5 & 17.5 & 2.6 \\
future & $40.8^{*}$ & 10.3 & 10.1 & 5.8 & 4.8 & 3.7 & 7.0 & 4.3 & 10.9 & 2.2 \\
historic & $22.3^{*}$ & 18.0 & 8.5 & 3.0 & 5.0 & 3.6 & 12.0 & 16.3 & 7.8 & 3.6 \\
intrinsic & $40.1^{*}$ & 9.5 & 10.7 & 6.0 & 5.1 & 8.0 & 6.6 & 7.1 & 6.7 & 0.1 \\
learning & $42.2^{*}$ & 10.0 & 8.9 & 3.6 & 7.3 & 2.2 & 8.5 & 3.1 & 11.0 & 3.1 \\
life sustaining & $44.0^{*}$ & 9.8 & 9.0 & 5.9 & 3.3 & 4.7 & 7.3 & 6.2 & 8.6 & 1.3 \\
recreation & $38.7^{*}$ & 12.3 & 7.4 & 3.4 & 3.2 & 2.7 & 7.9 & 8.5 & 10.6 & 5.3 \\
spiritual & $20.8^{*}$ & 17.7 & 17.0 & 4.6 & 5.1 & 4.9 & 11.7 & 1.5 & 4.4 & 0.2 \\
subsistence & $43.5^{*}$ & 10.2 & 7.7 & 3.8 & 3.0 & 3.2 & 8.2 & 8.1 & 8.2 & 4.1 \\
\hline
\end{tabular}

* Factors that contribute the most. Note: Distance to stream (DS); Distance to road (Dr); Distance to agricultural land (Da); Distance to forest (Df); Distance to built-up (Dbt); Distance to grassland (Dg); Distance to bare land (Db); Distance to water body (Dw); Land Use and Land Cover type (LULC).

Table 4 shows the reliability results of the crowdsourced survey analysis. Please note that the overall value of Cronbach's alpha is 0.80 .

Table 4. Measures of crowdsource survey reliability.

\begin{tabular}{|c|c|c|c|c|}
\hline Question Sets & $\begin{array}{l}\text { Scale Mean If } \\
\text { Related Questions } \\
\text { Are Deleted }\end{array}$ & $\begin{array}{l}\text { Scale Variance If } \\
\text { Related Questions } \\
\text { Are Deleted }\end{array}$ & $\begin{array}{c}\text { Correlated } \\
\text { Question in Total } \\
\text { Correlation }\end{array}$ & $\begin{array}{l}\text { Cronbach's Alpha If } \\
\text { Related Questions } \\
\text { Are Deleted }\end{array}$ \\
\hline $\begin{array}{l}\text { Questions related to } \\
\text { environment }\end{array}$ & 7.24 & 3.78 & 0.54 & 0.78 \\
\hline $\begin{array}{l}\text { Questions related to } \\
\text { the culture and history }\end{array}$ & 7.49 & 3.56 & 0.61 & 0.75 \\
\hline $\begin{array}{l}\text { Questions related to } \\
\text { community activities }\end{array}$ & 7.71 & 3.35 & 0.60 & 0.76 \\
\hline $\begin{array}{l}\text { Questions related to } \\
\text { economic activities }\end{array}$ & 7.56 & 3.65 & 0.72 & 0.71 \\
\hline
\end{tabular}

Note: base level Cronbach's alpha with all crowdsource survey questions included equal to 0.8 .

\subsection{Spatial Prioritization}

Six scenarios for prioritized conservation areas based on BpS, SV, and development preferences are considered. Figure 5a shows the geographical distribution of the top 30\%, 20\% and 10\% conservation areas when only BpS are considered. The high priority areas are located primarily in the south, some of which are scattered near the river. Figure $5 \mathrm{~b}$ shows the top $30 \%, 20 \%$ and $10 \%$ priority conservation areas mapped with only SV considered. In this scenario, the areas closest to the stream are identified as top priority conservation areas. Moreover, Figure $5 c$, which maps priority conservation areas based on both BpS and SV, shows a higher proportion of high priority areas in the southern Datuan Stream area when compared to Figure 5b. In Figure 5d, the spatial distribution of development preference is shown, designating the north as the preferred location of any future development. Figure 5e maps priority conservation areas when $\mathrm{BpS}$ and SV are both considered in protection area allocation while development preference is considered to be a cost. Because areas in the north maintained both high SV and high development preference, in this scenario the top priority conservation areas consequently shifted to the south. Further, Figure $5 \mathrm{f}$ maps the top 30\%, 20\%, and $10 \%$ priority conservation areas when both BpS and SV are considered after the development preference areas mapped in Figure $5 \mathrm{~d}$ are excluded (blue area). When the north is no longer an option to be considered as area dedicated to conservation, high priority conservation areas shift to areas along the stream. 


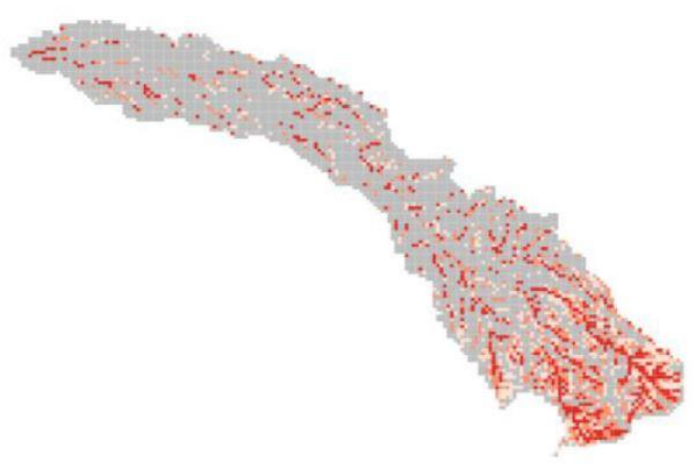

(a)

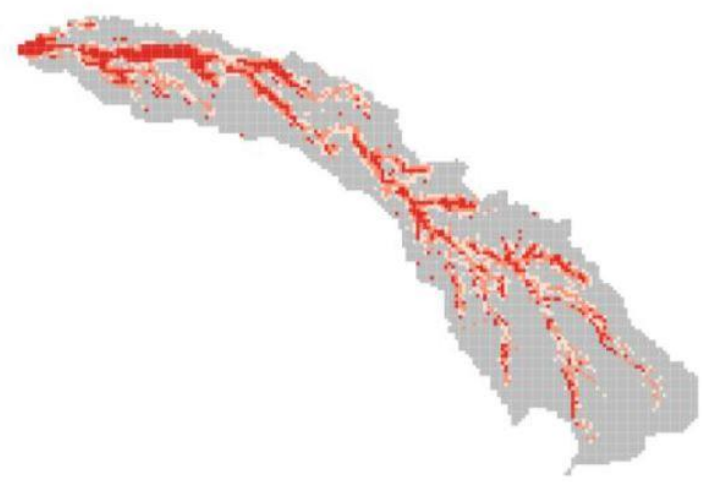

(c)

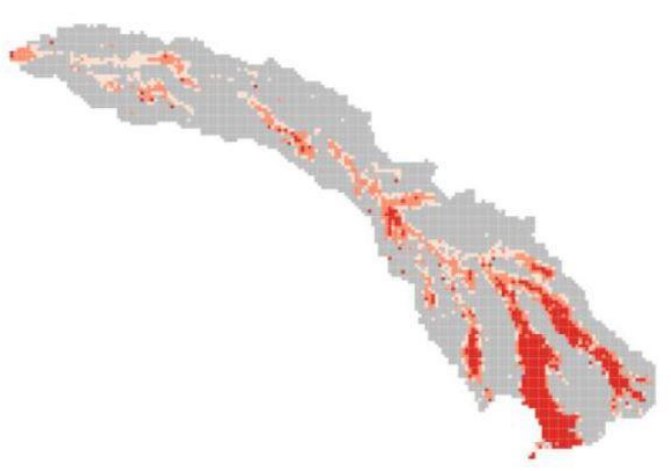

(e)

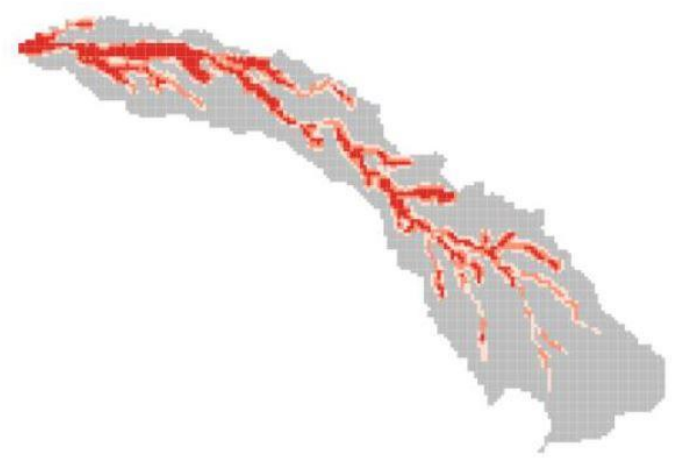

(b)

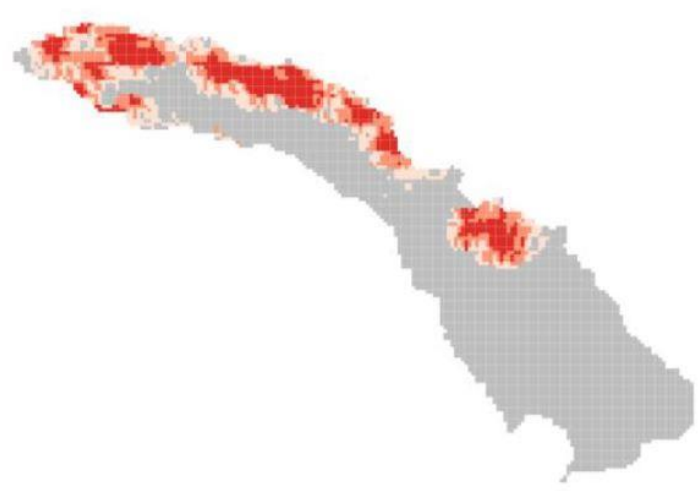

(d)

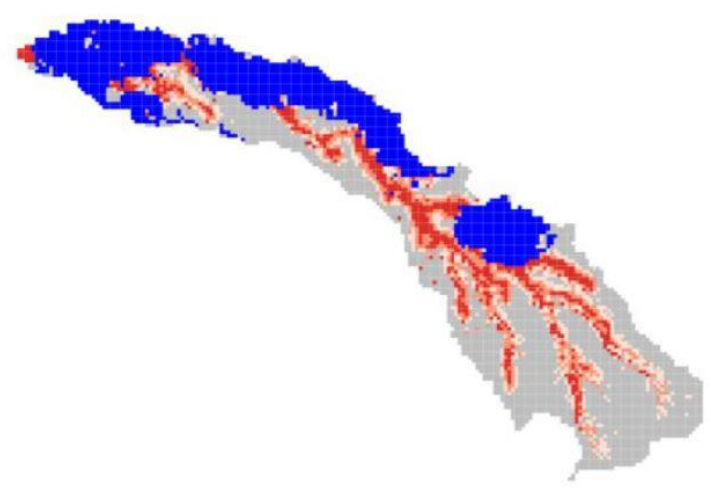

(f)

Figure 5. Geographical distributions of top 30\% (red), 20\% (light red) and 10\% (pale red) conservation areas as determined by zonation based on (a) BpS only; (b) SV only, (c) BpS and SV; (d) development preference only; (e) BpS and SV as protected targets, and development preference as a cost; (f) BpS and SV considered after high development suitability areas (over $70 \%$ probability of being converted to built-up area) are excluded (blue area). Note: Biophysical Services (BpS); Social Values (SV); grey color represents background. 
Table 5 illustrates each of the proportions derived from the six spatial prioritized conservation area scenarios discussed above. In Scenarios 1 and 2, the top 30\% high priority conservation areas have proportionally higher BpS ("BpS 1-6") and SV ("SV 1-12") respectively since the corresponding spatial prioritization scenarios (Figure 4a,b) considered only BpS and SV. In scenario 3, target conservation areas have high proportions of both BpS and SV. The proportion of development preference ("built-up") is high in scenario 4, relative to BpS and SV. In both Scenarios 5 and 6, development preference is proportionally lower than in scenario 3. Figures S7 and S8 (see Supplementary Materials) show similar tendencies in the top $20 \%$ and $10 \%$ high priority conservation areas that have proportionally higher BpS and SV respectively since the corresponding spatial prioritization scenarios (Figure 4a,b) considered only BpS and SV. The histograms of the proportions of $\mathrm{BpS}$ and SV, and development preference in the top 10, 20 and 30 percent target conservation areas for six different scenarios are also shown in the supplementary material.

Table 5. Proportions for six conservation scenarios, as mentioned in Table 1, of BpS, SV, and development preference in the top $30 \%$ target conservation areas.

\begin{tabular}{ccccccc}
\hline Outputs & Scenario 1 & Scenario 2 & Scenario 3 & Scenario 4 & Scenario 5 & Scenario 6 \\
\hline BpS1 & 0.375 & 0.25 & 0.272 & 0.26 & 0.316 & 0.305 \\
BpS2 & 0.583 & 0.086 & 0.136 & 0.052 & 0.395 & 0.239 \\
BpS3 & 0.899 & 0.369 & 0.735 & 0.355 & 0.628 & 0.521 \\
BpS4 & 0.884 & 0.307 & 0.617 & 0.289 & 0.577 & 0.506 \\
BpS5 & 0.865 & 0.173 & 0.477 & 0.096 & 0.586 & 0.553 \\
BpS6 & 0.293 & 0.311 & 0.308 & 0.304 & 0.302 & 0.304 \\
SV1 & 0.210 & 0.696 & 0.663 & 0.421 & 0.497 & 0.489 \\
SV2 & 0.214 & 0.713 & 0.682 & 0.424 & 0.517 & 0.492 \\
SV3 & 0.218 & 0.690 & 0.660 & 0.407 & 0.508 & 0.499 \\
SV4 & 0.212 & 0.700 & 0.668 & 0.413 & 0.508 & 0.499 \\
SV5 & 0.219 & 0.677 & 0.647 & 0.409 & 0.495 & 0.490 \\
SV6 & 0.221 & 0.676 & 0.646 & 0.404 & 0.500 & 0.494 \\
SV7 & 0.225 & 0.701 & 0.673 & 0.401 & 0.527 & 0.513 \\
SV8 & 0.210 & 0.682 & 0.649 & 0.423 & 0.484 & 0.479 \\
SV9 & 0.220 & 0.714 & 0.685 & 0.407 & 0.533 & 0.512 \\
SV10 & 0.219 & 0.694 & 0.664 & 0.404 & 0.512 & 0.505 \\
SV11 & 0.222 & 0.679 & 0.65 & 0.400 & 0.504 & 0.500 \\
SV12 & 0.219 & 0.677 & 0.647 & 0.409 & 0.495 & 0.490 \\
built-up & 0.196 & 0.388 & 0.367 & 0.510 & 0.219 & 0.250 \\
\hline
\end{tabular}

Note: Biophysical Services (BpS); Social Values (SV); Development preference (built-up).

\subsection{Social-Ecological Matrix}

Figure 6 represents four Social-Ecological Matrices corresponding to alternate Zonation overlap outputs for both BpS and SV. The corresponding categories consist of high SV-high BpS (high-high), high SV-low BpS (high-low), low SV-high BpS (low-high), and low SV-low BpS (low-low). Table 5 shows the proportion of land covered by each category. Note that, in this study, we chose a Zonation threshold of top 30\% to represent high priority areas, but other thresholds are possible. Table 6 shows the proportion of the study areas for each category. 


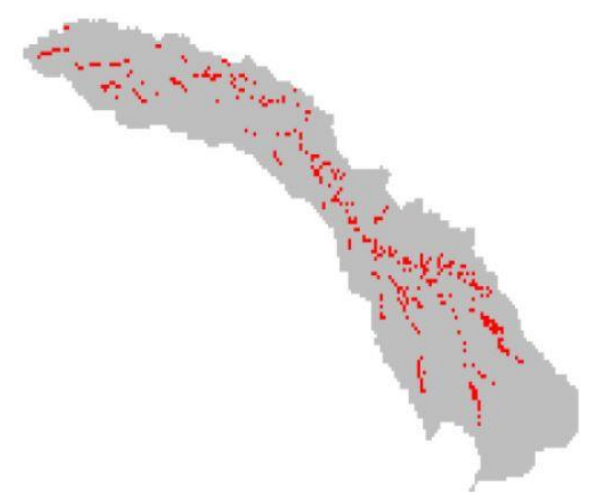

(a)

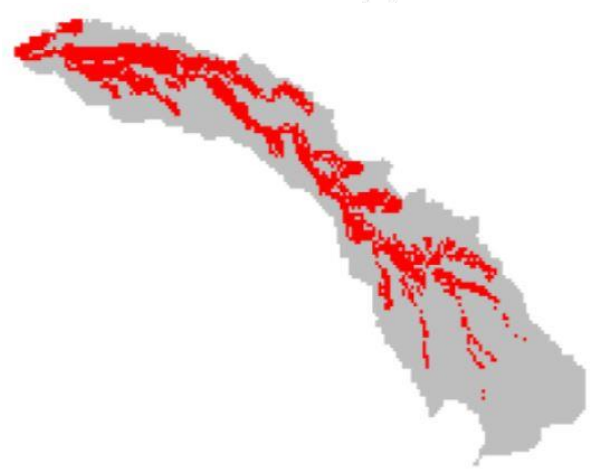

(c)

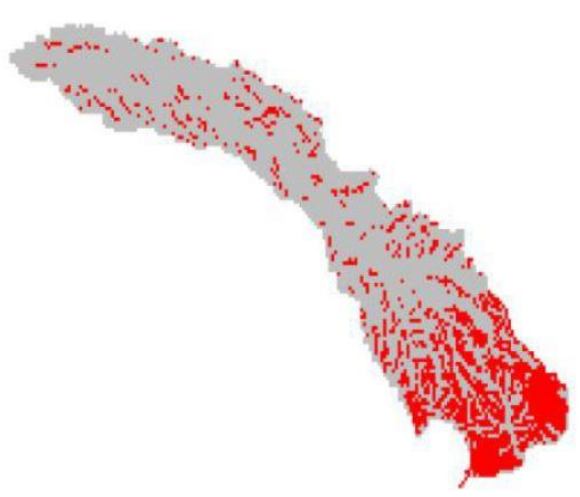

(b)

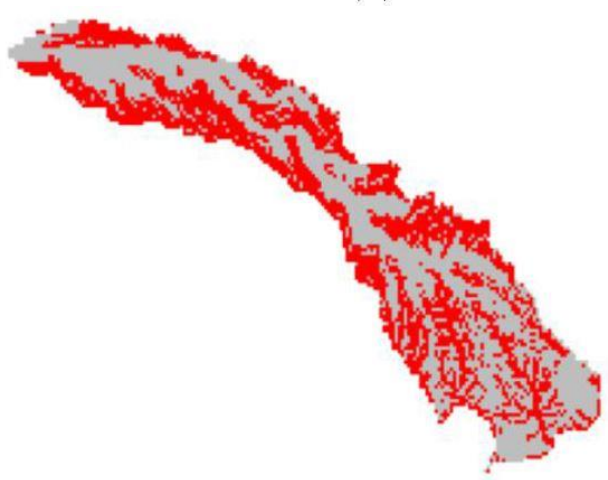

(d)

Figure 6. Social-Ecological Matrix maps with SV and BpS corresponding to 4 categories (in red) (a) High-High, i.e., top 30\% zonation results areas of both SV and BpS correspond with one another, (b) Low-High, (c) High-Low, and (d) Low-Low. (Grey color represents background). Note: Social Values (SV); Biophysical Services (BpS).

Table 6. Proportion of the entire study area covered by each social-ecological category.

\begin{tabular}{cccc}
\hline \multirow{2}{*}{ Ecosystem Services } & \multicolumn{2}{c}{ Biophysical Services } \\
\cline { 3 - 4 } & & High & Low \\
\hline \multirow{2}{*}{ Social Values } & High & 0.0554 & 0.2445 \\
\cline { 2 - 4 } & Low & 0.2445 & 0.4555 \\
\hline
\end{tabular}

\section{Discussion}

\subsection{Spatial Distributions of Biophysical Services and Social Values}

The significant role that social-ecological linkages play in sustainable ecosystem management is widely recognized by sustainability scientists, policy makers, and other stakeholders [4]. The estimated spatial distributions of BpS and SV in this study indicate that each occurs in distinct spatial patterns though certain ES are linked to the Datuan Stream due to local anthropogenic activities and LULC-i.e., nitrogen retention, phosphorus retention, soil retention, and the array of SV. The distributions of individual services and clusters of ES are also strongly linked to urbanization [13,49] as well as to physical characteristics such as the distributions of rainfall and variations in elevation. In terms of carbon storage estimates, for example, the strong link observed with LULC is attributable to the dependence the InVEST model has on LULC type when quantifying the carbon pool stored in each cell. Therefore, the results are highly dependent on the LULC classification used. Although this model assumption is valid, since carbon storage among LULC types differ greatly, there is also 
significant variation within LULC types. For example, carbon storage within tropical forests are affected by variables such as temperature, elevation, rainfall, and the number of years since a major disturbance. One way to reduce these effects is the sub classification of LULC types into distinct carbon pool categories that allow for greater detail, e.g., altitude, climatic conditions, or years since major disturbances such as wildfires, deforestation events, etc. However, this requires additional data and analysis [14]. Other BpS are determined by a greater number of biophysical processes, and are, therefore, not as strongly linked with LULC classification. This is also evident in our results.

Our results also show a strong link between SV and the Datuan Stream. Furthermore, the zonation conservation scenario "BpS and SV" identifies the area along the Datuan Stream as having the highest priority. We can interpret this to mean that in general, local residents value accessibility to the Datuan Stream most. Unlike the findings of previous studies, $[36,43,64]$ the SV spatial distributions found in this study are highly correlated with man-made landscape features within the ecosystem rather than biotic components. In this case, a riverside pathway, religious structures, and agricultural areas (see photos and locations in the Supplementary) were valued most.

Cultural and spiritual values appeared more related to landscapes with urban features and infrastructure, as well as trees, shrubs, and agriculture $[33,36,65]$. This may be due to our crowdsourcing approach, which may capture cultural heritage, existence values, and spiritual values differently since we include social media photographs in the surveys (Maps in Supplementary). Despite this, the distribution of SV are by no means identical, and can be linked to a number of factors, such as LULC, urbanization, climatic and physical characteristics, e.g., the distributions of rainfall and variations in elevation [13,49]. In this way, our SV results are similar to those of other studies [33,36], in that variations in SV are highly context-specific [36,37].

Beyond increasing participatory decision-making, the crowdsourced approach used in this study can reduce the negative consequences of decisions based solely on scientific information, which often suffer from limited public consensus $[49,66,67]$. Facebook was used in the SV surveys of this study. Compared with using Flickr [36] in cultural ES evaluations, Facebook provides greater flexibility and offers a wider range of languages, in this case traditional Chinese. In future cultural ES assessments and landscape perception studies, differences between social media platforms should be evaluated [36]. It is also essential to validate crowdsourced data [36]. With the high Cronbach's alpha value- 0.8 -found in this study, we concluded that the Likert scale and questions exhibit a high level of internal consistency. Moreover, the Cronbach's alpha results show that all survey questions should be retained since removal of any set of questions, related to one of four SV categories, from the SV questionnaire produced a lower Cronbach's alpha value. In this study, the training AUC values ( $>0.97)$ also indicated that the Maxent model fit the primary study area exceptionally well, while the test AUC values $(>0.95)$ indicated the potential performance of the model in transferring SV outputs to similar areas [58]. Despite some differences in survey design, $\mathrm{Li}$ [53] also found that the 12 SV distributions generated by both in depth PPGIS surveys (64 samples) and the crowdsourced data ( 85 samples used in this study) were spatially consistent enough to merit joining them. Specifically, the Kappa values ranged from 0.73 to 0.86 , except for the spiritual and historical SV, which were 0.63 and 0.59 , respectively [53].

This study also demonstrated that areas with the most significant habitat or carbon storage services are not necessarily those best suited to maximizing runoff mitigation (Figure 3). This particular result is mainly due to LULC types being major factors in the capacity to absorb precipitation. While habitat-forest, in this study-is driven by both LULC type and proximity to other habitats, carbon storage is simply driven by vegetation. Similarly, when mapping SV (Figure 4), it is clear that SV also varies, although not to the same extent as BpS. While access to green spaces, or the lack thereof, is evident across different districts, high SV is more concentrated in specific boroughs and in local neighborhoods within the districts, indicated by population density and median income indicators [30] (Figure 3). However, the spatial distributions of all ES taken together, i.e., SV and BpS, in the study area indicate that development of useful approaches to social-ecological system management could pose a persistent challenge due to the complexity of spatially matching SV and BpS [68]. Therefore, 
given the complexity of socioecological systems [11], new approaches-such as the proposed approach in this study-are required to foster synergy between SV and BpS.

\subsection{Spatial Prioritization of Biophysical Services and Social Values}

It is essential that ES values are prioritized to quantify ES benefits for human well-being and to inform management-level policy decisions [26,44]. To date, there have been a number of approaches developed to generate social-ecological values in spatially explicit, informative, and representative ways [69]. Our results indicate that SCP zonation can also be used to provide prioritization of social-ecological conservation areas based on diverse valuations of SV and BpS. The prioritization maps also provided the spatial context necessary for (1) evaluating the relationship between the intensity of SV and the underlying physical environmental characteristics; (2) a possible framework to investigate spatial correlations between socioeconomic and biophysical variables (e.g., De Lange et al. [9]; Sherrouse et al. [21]; Whitehead et al. [3]); and (3) social-ecological planning. The spatial distributions of conservation priorities based on the six scenarios, SV and BpS (Figure 4, Figures S4-S6, and Tables S4 and S5) can indicate where areas suitable for development coincide with areas of conservation importance. These high-risk areas are potential conservation conflict zones and require careful planning to avert ES loss [3]. For example, the spatial data can provide useful information to minimize land-use conflict by revealing areas where there is high development suitability but low SV and BpS [3,70].

These types of trade-offs among multiple ES including SV and BpS across landscapes are major issues in ecosystem planning and management [71,72]. The social-ecological valuation method presented here can be used as a valuable framework for quantifying the trade-offs among competing alternatives [72]. It can also increase our understanding of the sociopolitical dimensions of ES management and planning [72,73]. In addition, the results of our SCP approach are comparable to those of other studies $[71,72]$ in highlighting the imminence of compromise when considering multiple ES. An additional finding that corresponds to other studies is the discrepancy between social-ecological ES when heterogeneous landscape types, represented as LULC in this study, are considered [67].

\subsection{Limitations of the Case Study}

This study aims to minimize biases by integrating both local and scientific knowledge. By using the validated crowdsourced dataset presented by Li [53], we reduced the potential for valuation assignments by participants who are unfamiliar with the study area or who perfunctorily filled out the survey. It is possible, however, that biases are detectable in the selection of a temple as one of the reference location sites identified by the elected leaders. Despite this, the assigned temple in this study, which has a high SV but low BpS value even though it is located in a natural setting, reveals how framing ES valuations within a human and natural system could increase public support for conservation policies [74] since valuations are shaped by worldviews [75]. Furthermore, the choice of reference locations that fall along the Datuan Stream reflects the biophysical, socio-cultural, and economic tradeoff complexities made when valuating nature [76]. Accordingly, social-ecological data should supplement conservation modeling and expert opinion [35]. In recent years, crowdsoucing approaches have been widely applied in SV studies [35]. Nonetheless, it is important to critically assess the results of these types of surveys [36]. For instance, one of the main results of this study-the disconnect between BpS and SV_could, to some degree, reflect survey location selection [67]. Alternatively, the disconnect may be due to a knowledge variable that accounts for variation in perceived biodiversity values [77]. Van Riper et al. [75] sub-grouped respondents into "low knowledge" and "high knowledge" categories based on their self-reported knowledge level of the study area. The study found that participants who self-reported a "low knowledge" base, valued biodiversity within the study area only at those locations they frequented the most. If a location had a high degree of biodiversity but was located in an area the participant infrequently visited, the area was less likely to valued. Their study revealed that values held by a participant, i.e., environmental 
worldview, influences how they map ES. Participants with an anthropocentric orientation mapped with utilitarian tendencies while those with biocentric orientations mapped ES regardless of previous direct experience with specific locations [75]. Furthermore, as demonstrated in previous studies [78], the public generally lacks adequate knowledge about biophysical characteristics of a given area. The dataset used in this study, may reflect some of the above concerns. For example, while most spatial distributions of SV were found to have high Kappa values, the low Kappa values of spiritual and historical SV presented by Li [53] may reflect differences in the worldview and knowledge of PPGIS and crowdsourced participants. Nevertheless, the use of crowdsourced data and the findings of this study may substantiate the importance of top-down and bottom-up approaches when considering ES, as identified by Brown et al. [35]. Other studies have noted that biases are not limited to crowdsourced data, in fact narrow PPGIS participant selection may also lead to mapping biases. For example, participants who act to further external objectives for political or economic motivations; community influencers who may sway public perception; and participatory shifts during various stages of the project may impact outcomes [79]. In the case of conservation planning, data produced by PPGIS crowd-sourcing methods have been identified as being 'good enough' but require further refinement or validation [35]. In previous studies, inherent geographical and demographic biases in crowdsourced data have also been explored $[31,80,81]$. The need for effective tools and techniques for bias analysis that can improve citizen science data quality has also been discussed [31].

\subsection{Social-Ecological Matrix Analysis}

The ES maps produced by this study exemplify an important observation regarding ES in the context of planning and urban governance, namely, that there are tradeoffs and synergies among various ES. By first prioritizing high value locations of SV and BpS via zonation, it is possible to avoid difficulties with making comparisons between different measurement units. The efficacy of the proposed conservation area selection strategy is satisfactorily demonstrated in this study, particularly when determining conservation and urban development goals with competing priorities. When assessed in total and represented as spatially distributed overlays based on the Social-Ecological Matrix, the ES valuation approach presented in this study is not only complementary to current ecosystem modeling approaches, but is also more effective at conveying the intrinsic dynamics of a complex social-ecological system. This information may be instrumental in elucidating important measures that could improve community interaction or understanding of local ecosystems. For example, in this study we found that areas of high BpS but low SV are located in densely forested interior areas. Conversely, the walkway along the Datuan Stream where people spend most of their time is an area of low BpS but high SV. While this may not be surprising, with this knowledge in hand, there may be more incentives to educate the public about the importance of these interior areas, e.g., targeted education about nesting sites for eagles, etc.

Appropriate social-ecological approaches could be useful in achieving ES-based management [11-13,24], the difficulties of which are due to the ramifications of aggregating multiple SV and BpS [63]. Unlike Mcphearson et al. [63] who used Social-Ecological Matrix with standardized values ranging 1-10 and normalized values 0-100 [29], the methodology used in this study is similar to the PPGIS method employed by Whitehead et al. [3]. This study differs from the above, however, in that it quantifies and prioritizes SV and BpS with an integrated prioritization system rather than the typical method of prioritizing SV, BpS, or economic valuation individually. By concurrently focusing on both SV and BpS, understanding which social and ecological provision-and-benefit combinations are required to produce and sustain ES becomes less elusive. While Bryan et al. [24] noted that conservation actions in areas of high BpS value and high SV require minimal additional community engagement for success, in this study, we found that a small proportion of area (5.5\% of the total area) had both high BpS priority and high SV. Furthermore, such areas were directly linked to two important factors-the Datuan Stream and human activities. Likewise, deconstructing stacked indices (see Figure 6 and Figure S7) can facilitate the maximization of ES given 
specific in situ conditions. A scenario in which there is more than one land use project proposal among residents, or groups, who share the area and ES would also benefit from this analysis. Moreover, the outcomes of all scenarios based on our approach could benefit social-ecological planning in general.

\section{Conclusions}

Spatially explicit analyses of social-ecological systems enable the quantification of social and ecological variables in ways that can be useful for visualization, for stacking ES, and for identifying priority areas for social-ecological planning. In this study, we proposed a novel approach that can simultaneously consider a broad range of BpS and SV. The approach was used to compare, contrast, and integrate the results of ecologically and socially relevant ecosystem service priority areas, and high-suitability development areas. We then discussed the drivers, implications and potential conflicts revealed by the approach. The proposed systematic conservation strategy is novel in that it provides a framework that can integrate a wider range of ES, i.e., one that includes both social and ecological value systems, thereby facilitating a type of spatial prioritization method for conservation area selection suitable for use by multiple stakeholders. Moreover, this study maintains that combining SV (as calculated by SolVES) and ecologically important BpS (as calculated by InVEST) yield results that are highly informative to stakeholders and decision makers.

Supplementary Materials: The following are available online at www.mdpi.com/2071-1050/9/5/718/s1. Table S1: The definitions of social values of ecosystem services taken from 11 Clement and Cheng; Table S2: Questions and contents of the questionnaire; Table S3: Type of survey sites considered in the research area; Table S4: The ID of each survey site type; Table S5: Area Under the Curve (AUC) values for Maxent training and test data sets; Figure S1: Overview of questionnaire design; Figure S2: Respondent demographics and familiarity with research area results; Figure S3: A number of locations that highlight the natural beauty and diversity of the Datuan watershed (a) a site from the upstream area; (b) a site from the upstream area; (c) a site from the midstream area; (d) a site from the midstream area; (e) a site from the downstream area; (f) a site from the downstream area; Figure S4: Locations that are perceived as having high social value within the Datuan Watershed (a) along the Datuan Stream; (b) Paddy fields; (c) Terraces; (d) Lotus field; (e) ancestry memorial park; (f) Weir downstream of Datuan stream; (g) Estuary of Datuan stream; (h) Coastal intertidal zone; (i) a café shop for art exhibitions; (j) 100-year old historical house; (k) irrigation channel; (l) Wisteria Café shop; (m) Taoist temple; (n) Buddhist temple; (o) Temple of Land God; (p) Liukuaicuo fishing port; (q) Shanfu bridge; (r) ecological pool; (s) Stone House; (t) trail; (u) A sign explaining local ecological ; (v) Datuan Stream historical road; (w) Li's Yanlou(old historical house); (x) Recreational tourist farm; (y) Eco-engineering park; (z) Memorial park; (aa) School; (ab) pottery factory; (ac) Sanbanqiao bridge; Figure S5: Locations of high natural and social value survey sites (Li [5]).; Figure S6: Generalized process flow of social values map generation. (Sherrouse 196 and Semmens [8] and Hsin-Yi $\mathrm{Li}$ [5]); Figure S7: Spatial distributions of SV in (a) aesthetic; (b) biological diversity; (c) cultural; (d) economic; (e) future; (f) historic; (g) intrinsic; (h) learning; (i) life sustaining; (j) recreation; (k) spiritual; (l) subsistence values.; Figure S8: Proportions of ecosystem services, social values, and development preferences in the top $30 \%$ target conservation areas for six different scenarios; Figure S9: Proportions of ecosystem services and social values, and development preference in the top 20\% target conservation areas for six different scenarios; Figure S10: Proportions of ecosystem services and social values, and development preference in the top $10 \%$ target conservation areas for six different scenarios.

Acknowledgments: The authors would like to thank the Ministry of Science and Technology of the Republic of China, Taiwan, for financially supporting this research under Contract Nos. 100-2410-H-002-196-MY3 and 103-2410-H-002-161-MY3. The authors would also like to acknowledge Hsin-Ya Lin, from National Taiwan University, Taiwan, Taipei, for her excellent editing work.

Author Contributions: The scope of this study was developed by Yu-Pin Lin. The first manuscript draft was written by Yu-Pin Lin and Wei-Chih Lin, and was substantially revised by Yu-Pin Lin, Wei-Chih Lin, Yung-Chieh Wang, Wan-Yu Lien, Johnathen Anthony and Joy R. Petway. The modeling works have been done by Wei-Chih Lin, Yu-Pin Lin, Hsin-Yi Li and Chih-Chen Hsu. Hsin-Yi Li and Yu-Pin Lin did SV design and survey.

Conflicts of Interest: The authors declare no conflict of interest.

\section{References}

1. Daily, G. Nature's Services: Societal Dependence on Natural Ecosystems; Island Press: Washington, DC, USA, 1997.

2. Fisher, B.; Turner, K.; Zylstra, M.; Brouwer, R.; Groot, R.; Farber, S.; Ferraro, P.; Green, R.; Hadley, D.; Harlow, J. Ecosystem services and economic theory: Integration for policy-relevant research. Ecol. Appl. 2008, 18, 2050-2067. [CrossRef] [PubMed] 
3. Whitehead, A.L.; Kujala, H.; Ives, C.D.; Gordon, A.; Lentini, P.E.; Wintle, B.A.; Nicholson, E.; Raymond, C.M. Integrating biological and social values when prioritizing places for biodiversity conservation. Conserv. Biol. 2014, 28, 992-1003. [CrossRef] [PubMed]

4. Fischer, J.; Gardner, T.A.; Bennett, E.M.; Balvanera, P.; Biggs, R.; Carpenter, S.; Daw, T.; Folke, C.; Hill, R.; Hughes, T.P.; et al. Advancing sustainability through mainstreaming a social-ecological systems perspective. Curr. Opin. Environ. Sustain. 2015, 14, 144-149. [CrossRef]

5. Villa, F.; Bagstad, K.J.; Voigt, B.; Johnson, G.W.; Portela, R.; Honzak, M.; Batker, D. A methodology for adaptable and robust ecosystem services assessment. PLoS ONE 2014, 9. [CrossRef] [PubMed]

6. Carpenter, S.R.; Mooney, H.A.; Agard, J.; Capistrano, D.; DeFries, R.S.; Diaz, S.; Dietz, T.; Duraiappah, A.K.; Oteng-Yeboah, A.; Pereira, H.M.; et al. Science for managing ecosystem services: Beyond the millennium ecosystem assessment. Proc. Natl. Acad. Sci. USA 2009, 106, 1305-1312. [CrossRef] [PubMed]

7. Diaz, S.; Demissew, S.; Carabias, J.; Joly, C.; Lonsdale, M.; Ash, N.; Larigauderie, A.; Adhikari, J.R.; Arico, S.; Baldi, A.; et al. The ipbes conceptual framework—connecting nature and people. Curr. Opin. Environ. Sustain. 2015, 14, 1-16. [CrossRef]

8. Bennett, E.M.; Cramer, W.; Begossi, A.; Cundill, G.; Diaz, S.; Egoh, B.N.; Geijzendorffer, I.R.; Krug, C.B.; Lavorel, S.; Lazos, E.; et al. Linking biodiversity, ecosystem services, and human well-being: Three challenges for designing research for sustainability. Curr. Opin. Environ. Sustain. 2015, 14, 76-85. [CrossRef]

9. De Lange, W.J.; Wise, R.M.; Forsyth, G.G.; Nahman, A. Integrating socio-economic and biophysical data to support water allocations within river basins: An example from the Inkomati water management area in South Africa. Environ. Modell. Softw. 2010, 25, 43-50. [CrossRef]

10. BenDor, T.; Shoemaker, D.A.; Thill, J.C.; Dorning, M.A.; Meentemeyer, R.K. A mixed-methods analysis of social-ecological feedbacks between urbanization and forest persistence. Ecol. Soc. 2014, 19. [CrossRef]

11. Lescourret, F.; Magda, D.; Richard, G.; Adam-Blondon, A.F.; Bardy, M.; Baudry, J.; Doussan, I.; Dumont, B.; Lefevre, F.; Litrico, I.; et al. A social-ecological approach to managing multiple agro-ecosystem services. Curr. Opin. Environ. Sustain. 2015, 14, 68-75. [CrossRef]

12. Eisenmenger, N.; Giljum, S.; Lutter, S.; Marques, A.; Theurl, M.C.; Pereira, H.M.; Tukker, A. Towards a conceptual framework for social-ecological systems integrating biodiversity and ecosystem services with resource efficiency indicators. Sustainability 2016, 8, 201. [CrossRef]

13. Meacham, M.; Queiroz, C.; Norstrom, A.V.; Peterson, G.D. Social-ecological drivers of multiple ecosystem services: What variables explain patterns of ecosystem services across the norrstrom drainage basin? Ecol. Soc. 2016, 21, 14. [CrossRef]

14. Tallis, H.; Ricketts, T.; Guerry, A.; Nelson, E.; Ennaanay, D.; Wolny, S.; Olwero, N.; Vigerstol, K.; Pennington, D.; Mendoza, G. Invest 2.0 Beta User's Guide; The natural capital project; Stanford: Stanford, CA, USA, 2011.

15. Goldstein, J.H.; Caldarone, G.; Duarte, T.K.; Ennaanay, D.; Hannahs, N.; Mendoza, G.; Polasky, S.; Wolny, S.; Daily, G.C. Integrating ecosystem-service tradeoffs into land-use decisions. Proc. Natl. Acad. Sci. USA 2012, 109, 7565-7570. [CrossRef] [PubMed]

16. Nelson, E.; Sander, H.; Hawthorne, P.; Conte, M.; Ennaanay, D.; Wolny, S.; Manson, S.; Polasky, S. Projecting global land-use change and its effect on ecosystem service provision and biodiversity with simple models. PLOS ONE 2010, 5. [CrossRef] [PubMed]

17. Chiang, L.C.; Lin, Y.P.; Huang, T.; Schmeller, D.S.; Verburg, P.H.; Liu, Y.L.; Ding, T.S. Simulation of ecosystem service responses to multiple disturbances from an earthquake and several typhoons. Landsc. Urban Plan. 2014, 122, 41-55. [CrossRef]

18. Lin, Y.-P.; Lin, W.-C.; Wang, Y.-C.; Lien, W.-Y.; Huang, T.; Hsu, C.-C.; Schmeller, D.S.; Crossman, N.D. Systematically designating conservation areas for protecting habitat quality and multiple ecosystem services. Environ. Modell. Softw. 2017, 90, 126-146. [CrossRef]

19. Crossman, N.D.; Burkhard, B.; Nedkov, S.; Willemen, L.; Petz, K.; Palomo, I.; Drakou, E.G.; Martin-Lopez, B.; McPhearson, T.; Boyanova, K.; et al. A blueprint for mapping and modelling ecosystem services. Ecosyst. Serv. 2013, 4, 4-14. [CrossRef]

20. Brabham, D.C. Crowdsourcing; Mit Press: Cambridge, MA, USA, 2013.

21. Sherrouse, B.C.; Clement, J.M.; Semmens, D.J. A GIS application for assessing, mapping, and quantifying the social values of ecosystem services. Appl. Geogr. 2011, 31, 748-760. [CrossRef] 
22. Bagstad, K.J.; Semmens, D.J.; Waage, S.; Winthrop, R. A comparative assessment of decision-support tools for ecosystem services quantification and valuation. Ecosyst. Serv. 2013, 5, E27-E39. [CrossRef]

23. Daily, G.C.; Polasky, S.; Goldstein, J.; Kareiva, P.M.; Mooney, H.A.; Pejchar, L.; Ricketts, T.H.; Salzman, J.; Shallenberger, R. Ecosystem services in decision making: Time to deliver. Front. Ecol. Environ. 2009, 7, 21-28. [CrossRef]

24. Bryan, B.A.; Raymond, C.M.; Crossman, N.D.; King, D. Comparing spatially explicit ecological and social values for natural areas to identify effective conservation strategies. Conserv. Biol. 2011, 25, 172-181. [CrossRef] [PubMed]

25. Sherrouse, B.C.; Semmens, D.J.; Clement, J.M. An application of social values for ecosystem services (solves) to three national forests in colorado and wyoming. Ecol. Indic. 2014, 36, 68-79. [CrossRef]

26. Mastrangelo, M.E.; Weyland, F.; Herrera, L.P.; Villarino, S.H.; Barral, M.P.; Auer, A.D. Ecosystem services research in contrasting socio-ecological contexts of argentina: Critical assessment and future directions. Ecosyst. Serv. 2015, 16, 63-73. [CrossRef]

27. Plieninger, T.; Hartel, T.; Martin-Lopez, B.; Beaufoy, G.; Bergmeier, E.; Kirby, K.; Montero, M.J.; Moreno, G.; Oteros-Rozas, E.; Van Uytvanck, J. Wood-pastures of europe: Geographic coverage, social-ecological values, conservation management, and policy implications. Biol. Conserv. 2015, 190, 70-79. [CrossRef]

28. Boateng, P.K.; Appiah, D.O.; Adjei, P.O.-W.; Mensah, H.K. Perceptions of socio-ecological changes and their implications on changes in farming practises and agricultural land uses in the savannahs of northeast ghana. Environments 2016, 3, 33. [CrossRef]

29. Kremer, P.; Hamstead, Z.A.; McPhearson, T. The value of urban ecosystem services in New York city: A spatially explicit multicriteria analysis of landscape scale valuation scenarios. Environ. Sci. Policy 2016, 62, 57-68. [CrossRef]

30. Vojinovic, Z.; Keerakamolchai, W.; Weesakul, S.; Pudar, R.S.; Medina, N.; Alves, A. Combining ecosystem services with cost-benefit analysis for selection of green and grey infrastructure for flood protection in a cultural setting. Environments 2016, 4, 3. [CrossRef]

31. Lin, Y.-P.; Deng, D.; Lin, W.-C.; Lemmens, R.; Crossman, N.D.; Henle, K.; Schmeller, D.S. Uncertainty analysis of crowd-sourced and professionally collected field data used in species distribution models of taiwanese moths. Biol. Conserv. 2015, 181, 102-110. [CrossRef]

32. Papworth, S.; Nghiem, T.; Chimalakonda, D.; Posa, M.; Wijedasa, L.; Bickford, D.; Carrasco, L. Quantifying the role of online news in linking conservation research to facebook and twitter. Conserv. Biol. 2015, 29, 825-833. [CrossRef] [PubMed]

33. Richards, D.R.; Friess, D.A. A rapid indicator of cultural ecosystem service usage at a fine spatial scale: Content analysis of social media photographs. Ecol. Indic. 2015, 53, 187-195. [CrossRef]

34. Di Minin, E.; Tenkanen, H.; Toivonen, T. Prospects and challenges for social media data in conservation science. Front. Environ. Sci. 2015, 3, 63. [CrossRef]

35. Brown, G.; Weber, D.; de Bie, K. Is PPGIS good enough? An empirical evaluation of the quality of PPGIS crowd-sourced spatial data for conservation planning. Land Use Policy 2015, 43, 228-238. [CrossRef]

36. Oteros-Rozas, E.; Martín-López, B.; Fagerholm, N.; Bieling, C.; Plieninger, T. Using social media photos to explore the relation between cultural ecosystem services and landscape features across five European sites. Ecol. Indic. 2017. [CrossRef]

37. Casalegno, S.; Inger, R.; DeSilvey, C.; Gaston, K.J. Spatial covariance between aesthetic value \& other ecosystem services. PLOS ONE 2013, 8, e68437.

38. Brown, I.; Berry, P.; Everard, M.; Firbank, L.; Harrison, P.; Lundy, L.; Quine, C.; Rowan, J.; Wade, R.; Watts, K. Identifying robust response options to manage environmental change using an ecosystem approach: A stress-testing case study for the UK xxx. Environ. Sci. Policy 2015, 52, 74-88. [CrossRef]

39. Dunkel, A. Visualizing the perceived environment using crowdsourced photo geodata. Landsc. Urban Plan. 2015, 142, 173-186. [CrossRef]

40. Figueroa-Alfaro, R.W.; Tang, Z. Evaluating the aesthetic value of cultural ecosystem services by mapping geo-tagged photographs from social media data on panoramio and flickr. J. Environ. Plan. Manag. 2017, 60, 266-281. [CrossRef]

41. Tenerelli, P.; Demšar, U.; Luque, S. Crowdsourcing indicators for cultural ecosystem services: A geographically weighted approach for mountain landscapes. Ecol. Indic. 2016, 64, 237-248. [CrossRef] 
42. Gliozzo, G.; Pettorelli, N.; Haklay, M. Using crowdsourced imagery to detect cultural ecosystem services: A case study in South Wales, UK. Ecol. Soc. 2016, 21. [CrossRef]

43. Pastur, G.M.; Peri, P.L.; Lencinas, M.V.; Garcia-Llorente, M.; Martin-Lopez, B. Spatial patterns of cultural ecosystem services provision in southern Patagonia. Landsc. Ecol. 2016, 31, 383-399. [CrossRef]

44. Hicks, C.C.; Cinner, J.E.; Stoeckl, N.; McClanahan, T.R. Linking ecosystem services and human-values theory. Conserv. Biol. 2015, 29, 1471-1480. [CrossRef] [PubMed]

45. Davis, F.W.; Stoms, D.M.; Andelman, S. Systematic reserve selection in the USA: An example from the columbia plateau ecoregion. Parks 1999, 9, 31-41.

46. Moilanen, A.; Franco, A.M.A.; Early, R.I.; Fox, R.; Wintle, B.; Thomas, C.D. Prioritizing multiple-use landscapes for conservation: Methods for large multi-species planning problems. Proc. R. Soc. B Biol. Sci. 2005, 272, 1885-1891. [CrossRef] [PubMed]

47. Ban, N.C.; Mills, M.; Tam, J.; Hicks, C.C.; Klain, S.; Stoeckl, N.; Bottrill, M.C.; Levine, J.; Pressey, R.L.; Satterfield, T.; et al. A social-ecological approach to conservation planning: Embedding social considerations. Front. Ecol. Environ. 2013, 11, 194-202. [CrossRef]

48. De Groot, R.S.; Alkemade, R.; Braat, L.; Hein, L.; Willemen, L. Challenges in integrating the concept of ecosystem services and values in landscape planning, management and decision making. Ecol. Complex. 2010, 7, 260-272. [CrossRef]

49. Maes, J.; Egoh, B.; Willemen, L.; Liquete, C.; Vihervaara, P.; Schagner, J.P.; Grizzetti, B.; Drakou, E.G.; La Notte, A.; Zulian, G.; et al. Mapping ecosystem services for policy support and decision making in the European Union. Ecosyst. Serv. 2012, 1, 31-39. [CrossRef]

50. Martínez-Harms, M.J.; Balvanera, P. Methods for mapping ecosystem service supply: A review. Int. J. Biodivers. Sci. Ecosyst. Serv. Manag. 2012, 8, 17-25. [CrossRef]

51. Opdam, P. Using ecosystem services in community-based landscape planning: Science is not ready to deliver. In Landscape Ecology for Sustainable Environment and Culture; Springer: Dordrecht, The Netherlands, 2013; pp. 77-101.

52. Huntsinger, L.; Oviedo, J.L. Ecosystem services are social-ecological services in a traditional pastoral system: The case of California's mediterranean rangelands. Ecol. Soc. 2014, 19. [CrossRef]

53. Li, H.-Y. Using Ppgis and Crowdsourcing for Mapping Social Values for Ecosystem Services: The Case Study of Datuan Basin. Master's Thesis, National Taiwan University, Taipei, Taiwan, 2014.

54. Lin, Y.P.; Wang, C.L.; Chang, C.R.; Yu, H.H. Estimation of nested spatial patterns and seasonal variation in the longitudinal distribution of Sicyopterus japonicus in the Datuan Stream, Taiwan by using geostatistical methods. Environ. Monit. Assess. 2011, 178, 1-18. [CrossRef] [PubMed]

55. Brown, G.; Montag, J.M.; Lyon, K. Public participation GIS: A method for identifying ecosystem services. Soc. Nat. Resour. 2012, 25, 633-651. [CrossRef]

56. Fagerholm, N.; Kayhko, N.; Ndumbaro, F.; Khamis, M. Community stakeholders' knowledge in landscape assessments-Mapping indicators for landscape services. Ecol. Indic. 2012, 18, 421-433. [CrossRef]

57. Brown, G.; Reed, P. Validation of a forest values typology for use in national forest planning. For. Sci. 2000, $46,240-247$.

58. Sherrouse, B.C.; Semmens, D.J. Validating a method for transferring social values of ecosystem services between public lands in the rocky mountain region. Ecosyst. Serv. 2014, 8, 166-177. [CrossRef]

59. Sherrouse, B.C.; Semmens, D.J. Social Values for Ecosystem Services, Version 3.0 (Solves 3.0): Documentation and User Manual; US Geological Survey: Reston, VA, USA, 2015.

60. Lin, Y.P.; Chu, H.J.; Wu, C.F.; Verburg, P.H. Predictive ability of logistic regression, auto-logistic regression and neural network models in empirical land-use change modeling-A case study. Int. J. Geogr. Inf. Sci. 2011, 25, 65-87. [CrossRef]

61. Mikkonen, N.; Moilanen, A. Identification of top priority areas and management landscapes from a national natura 2000 network. Environ. Sci. Policy 2013, 27, 11-20. [CrossRef]

62. Moilanen, A. Landscape zonation, benefit functions and target-based planning: Unifying reserve selection strategies. Biol. Conserv. 2007, 134, 571-579. [CrossRef]

63. McPhearson, T.; Kremer, P.; Hamstead, Z.A. Mapping ecosystem services in New York City: Applying a social-ecological approach in urban vacant land. Ecosyst. Serv. 2013, 5, E11-E26. [CrossRef] 
64. Fagerholm, N.; Oteros-Rozas, E.; Raymond, C.M.; Torralba, M.; Moreno, G.; Plieninger, T. Assessing linkages between ecosystem services, land-use and well-being in an agroforestry landscape using public participation gis. Appl. Geogr. 2016, 74, 30-46. [CrossRef]

65. Zoderer, B.M.; Tasser, E.; Erb, K.H.; Stanghellini, P.S.L.; Tappeiner, U. Identifying and mapping the tourists' perception of cultural ecosystem services: A case study from an alpine region. Land Use Policy 2016, 56, 251-261. [CrossRef]

66. Castella, J.C.; Bourgoin, J.; Lestrelin, G.; Bouahom, B. A model of the science-practice-policy interface in participatory land-use planning: Lessons from Laos. Landsc. Ecol. 2014, 29, 1095-1107. [CrossRef]

67. Castro, A.J.; Verburg, P.H.; Martin-Lopez, B.; Garcia-Llorente, M.; Cabello, J.; Vaughn, C.C.; Lopez, E. Ecosystem service trade-offs from supply to social demand: A landscape-scale spatial analysis. Landsc. Urban Plan. 2014, 132, 102-110. [CrossRef]

68. Nair, S.S.; Preston, B.L.; King, A.W.; Mei, R. Using landscape typologies to model socioecological systems: Application to agriculture of the United States gulf coast. Environ. Modell. Softw. 2016, 79, 85-95. [CrossRef]

69. Kenter, J.O.; O'Brien, L.; Hockley, N.; Ravenscroft, N.; Fazey, I.; Irvine, K.N.; Reed, M.S.; Christie, M.; Brady, E.; Bryce, R.; et al. What are shared and social values of ecosystems? Ecol. Econ. 2015, 111, 86-99. [CrossRef]

70. Bekessy, S.A.; White, M.; Gordon, A.; Moilanen, A.; Mccarthy, M.A.; Wintle, B.A. Transparent planning for biodiversity and development in the urban fringe. Landsc. Urban Plan. 2012, 108, 140-149. [CrossRef]

71. Bennett, E.M.; Peterson, G.D.; Gordon, L.J. Understanding relationships among multiple ecosystem services. Ecol. Lett. 2009, 12, 1394-1404. [CrossRef] [PubMed]

72. Martin-Lopez, B.; Garcia-Llorente, M.; Palomo, I.; Montes, C. The conservation against development paradigm in protected areas: Valuation of ecosystem services in the Donana social-ecological system (southwestern Spain). Ecol. Econ. 2011, 70, 1481-1491. [CrossRef]

73. Anton, C.; Young, J.; Harrison, P.A.; Musche, M.; Bela, G.; Feld, C.K.; Harrington, R.; Haslett, J.R.; Pataki, G.; Rounsevell, M.D.A.; et al. Research needs for incorporating the ecosystem service approach into EU biodiversity conservation policy. Biodivers. Conserv. 2010, 19, 2979-2994. [CrossRef]

74. Mascia, M.B.; Brosius, J.P.; Dobson, T.A.; Forbes, B.C.; Horowitz, L.; McKean, M.A.; Turner, N.J. Conservation and the social sciences. Conserv. Biol. 2003, 17, 649-650. [CrossRef]

75. Van Riper, C.J.; Kyle, G.T. Capturing multiple values of ecosystem services shaped by environmental worldviews: A spatial analysis. J. Environ. Manag. 2014, 145, 374-384. [CrossRef] [PubMed]

76. Martín-López, B.; Gómez-Baggethun, E.; García-Llorente, M.; Montes, C. Trade-offs across value-domains in ecosystem services assessment. Ecol. Indic. 2014, 37, 220-228. [CrossRef]

77. Van Riper, C.J.; Kyle, G.T.; Sherrouse, B.C.; Bagstad, K.J.; Sutton, S.G. Toward an integrated understanding of perceived biodiversity values and environmental conditions in a national park. Ecol. Indic. 2017, 72, 278-287. [CrossRef]

78. Dallimer, M.; Irvine, K.N.; Skinner, A.M.J.; Davies, Z.G.; Rouquette, J.R.; Maltby, L.L.; Warren, P.H.; Armsworth, P.R.; Gaston, K.J. Biodiversity and the feel-good factor: Understanding associations between self-reported human well-being and species richness. Bioscience 2012, 62, 47-55. [CrossRef]

79. Schlossberg, M.; Shuford, E. Delineating "public" and "participation" in PPGIS. URISA J. 2005, 16, 15-26.

80. Maheshwari, D.; Janssen, M. Reconceptualizing measuring, benchmarking for improving interoperability in smart ecosystems: The effect of ubiquitous data and crowdsourcing. Gov. Inf. Q. 2014, 31, S84-S92. [CrossRef]

81. Crawford, K.; Finn, M. The limits of crisis data: Analytical and ethical challenges of using social and mobile data to understand disasters. Geojournal 2015, 80, 491-502. [CrossRef]

(c) 2017 by the authors. Licensee MDPI, Basel, Switzerland. This article is an open access article distributed under the terms and conditions of the Creative Commons Attribution (CC BY) license (http:/ / creativecommons.org/licenses/by/4.0/). 